\title{
OPTICAL ROTATION AS AN INDICATION OF AROMATIC SUBSTITUENT INFLUENCES AND INTRAMOLECULAR INTERACTION 1
}

\author{
By William Ward Pigman
}

\begin{abstract}
As a result of a comparison of the rotations of certain aromatic $\beta$-glucosides and their tetraacetates, it is shown to be probable that the rotations of the acetylated glucosides are influenced by steric interactions between the aglycon group and the sugar portion of the molecule. This behavior is in contrast to the influences predominating in the case of the unacetylated compounds which, as shown in previous work, probably operate on the resonance of the aglycon aromatic ring or in an inductive fashion.

As a test for the explanation of the anomalous positive rotations of certain of the acetylated $\beta$-glucosides, the rotation of several of these substances in nitrobenzene solution was measured over the temperature interval $20^{\circ}$ to $150^{\circ} \mathrm{C}$. Over this temperature range, several of the glucosides, and in particular those which show anomalous positive rotations at room temperature, exhibit a change in sign of rotation from positive to negative.

The preparation and properties of the following new compounds are described: The $m$-nitrophenyl $\alpha$-D-glucoside and its tetraacetate, the $o, p$ - and $o, o^{\prime}$-dinitrophenyl $\beta$-glucoside tetraacetates, and the $m$-nitrobenzyl $\beta$-glucoside tetraacetate. The rotatory dispersion of these and other glucosides is reported for five wavelengths over the visible spectrum.
\end{abstract}

\section{CONTENTS}

I. Introduction

II. Optical rotations of acetylated $\beta$-D-glucosides_....... 130 III. Nature of the "ortho effect" operative in the case of the acetylated phenyl $\beta$-glucosides.

2. Temperature influence

IV. Comparison of the rotations of the phenyl glucosides and of their tetraacetates...... 137

V. Measurement of the rotatory dispersions of some aromatic glucosides and of their tetraacetates..... 138

VI. Experimental procedure

1. Preparation of glucosides _...

(a) Substituted-phenyl D-glucosides

2. Optical-rotation measurements _...................... 141

(a) Influence of temperature

(b) Measurements of rotatory dispersion $\ldots \ldots \ldots \ldots$

\section{INTRODUCTION}

It has been demonstrated ${ }^{234}$ that the structures of the aromatic or alkyl radicals (the aglycon groups) of glycosides may be correlated

1 Portions of this paper were presented before the Division of Sugar Chemistry and Technology of the American Chemical Society in Detroit, Mich., April 1943.

2 C. S. Hudson, BS Sci. Pap. 21, 254 (1926) S533.

3 W. W. Pigman and H. S. Isbell, J. Research NBS 27, 9 (1941).RP1392.

${ }^{4} \mathrm{~L}$. C. Kreider and E. Friesen, J. Am. Chem. Soc, 61, 1482 (1942). 
with the optical rotations of the glycosides. Most of the correlations have been based on an ingenious method of comparison originated by Hudson, ${ }^{2}$ in which the molecular optical rotation (molecular weight $X[\alpha]_{\mathbf{D}}$ ) is divided into two parts - that caused by carbon 1 and that caused by the remainder of the molecule. In a previous paper (see footnote 3 ), it was shown that the molecular rotations of the $\beta$-glucosides can be used directly in such correlations. The use of the molecular rotation of a glucoside rather than the partial rotation of carbon 1 is possible, since the application of Hudson's isorotation rules shows (see footnote 3) the existence of a direct proportionality between these quantities for a series of related $\beta$-glucosides. The reason for this proportionality appears to be that the primary influence of structural changes in the aglycon group (group RO in the formula) is exerted on the asymmetric carbon to which it is directly connected. Although the molecule contains other asymmetric centers,

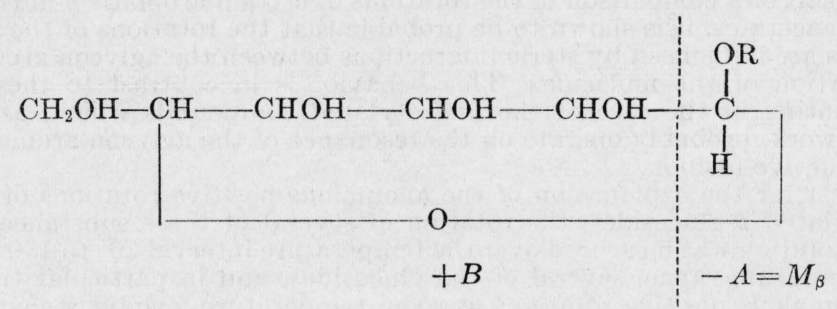

variations in the structure of the group $R$ have only a secondary and often negligible influence on the other centers. However, a marked difference in the influence of alkyl and aryl radicals on the partial rotations was noted; the aryl $\beta$-glucosides exhibit much more negative rotations than those of the alkyl $\beta$-glucosides, and both the partial rotations of carbon $1(A)$ and of the remaining asymmetric carbons $(B)$ are greater for the aryl than for the alkyl glucosides. Hence, it appears that the glucosides can be divided into two series-aryl and alkyl glucosides. The members of each of these series exhibit differences in the $A$ values (partial rotation of carbon 1). However, the $B$ value is the same for members in each of the series but differs for the two series.

In the previous work, the influence of structural changes in the aglyeon group on the optical rotations of the acetylated $\beta$-glucosides was not given much consideration. One reason for not considering the acetylated derivatives further was that after a superficial examination it was quickly seen that a correlation of the optical rotations is much more difficult for the acetylated than for the unacetylated compounds. The present paper is an extension of the previous investigation to acetylated glycosides. As will be shown, these compounds in many instances exhibit quite different optical rotations from those shown by the unacetylated glycosides.

\section{OPTICAL ROTATIONS OF ACETYLATED $\beta$-D-GLUCOSIDES}

The molecular rotations of a number of acetylated $\beta$-glucosides are compared in table 1 with the rotations of the unacetylated $\beta$-glucosides. Many of these values have been taken from the literature, but it was 
found necessary to prepare a number of new compounds and to remeasure the rotations of several more. The preparation of the new compounds and their properties are described in the experimental part of this paper. ${ }^{5}$

As noted in the previous paper, the aromatic $\beta$-glucosides have much more negative rotations than the corresponding alkyl glucosides. The value of $-9,000$ for the $n$-hexyl $\beta$-glucoside $(8)^{6}$ is typical of the rotations of the alkyl $\beta$-glucosides and that of $-18,200$ for the phenyl $\beta$ glucoside (1) is typical of many aromatic $\beta$-glucosides. The value for the benzyl $\beta$-glucoside (7), which has the aromatic nucleus removed from the glucosidic bond by a $\mathrm{CH}_{2}$ group, is intermediate in character between the $n$-hexyl and the phenyl $\beta$-glucosides. The introduction of an additional $\mathrm{CH}_{2}$ group gives phenylethyl $\beta$-glucoside (4), which has a rotation typical of that of the alkyl glucosides (8). Substitution of a nitro group in the aromatic ring of phenyl $\beta$-glucoside may take place in the ortho-, meta-, and para-positions, and each of the three possible compounds $(5,2$, and 6$)$ is considerably more levorotatory than the unsubstituted compound (1). It was shown in the previous paper that this influence of the nitro group (and of substituent groups in general, except some in the ortho-position) parallels the influence on the acidity of the corresponding phenols. It appears most likely that the influence of substituent groups is transmitted through the aromatic ring to the nearest asymmetric center (carbon 1). Evidence for the transmission of substituent effects through the chain is given by the near identity of the rotations of the $n$-hexyl and the phenylethyl $\beta$-glucosides ( 8 and 4 ); the intermediate values for the benzyl and $m$-nitrobenzyl $\beta$-glucosides (7 and 3) also agree with this interpretation.

It is evident from table 1 that the rotations of the $\beta$-glucosides in water are not paralleled by the rotations of the corresponding acetates in chloroform solution. Thus, the acetylated phenyl and the $n$-hexyl $\beta$-glucosides (9 and 18) have optical rotations of about the same magnitude; and the acetylated benzyl and $m$-nitrobenzyl $\beta$-glucosides (17 and 12) are much more levorotatory. The values for the nitrophenyl $\beta$-glucoside tetraacetates appear particularly anomalous when compared to those of the deacetylated compounds. Thus, although the meta- and para-isomers of the acetylated compounds (10 and 14) are more levorotatory than the unsubstituted compound (9), the ortho-isomer (15) not only is less negative but is dextrorotatory. There remains no doubt as to the value assigned to the ortho-isomer, for the original measurement by Glaser and Wulwek ${ }^{7}$ has been checked recently by Montgomery, Richtmyer, and Hudson, ${ }^{8}$ who also remark on its unusual positive sign.

\footnotetext{
${ }^{5}$ The $o$-nitro and $p$-nitrophenyl $\beta$-glucoside tetraacetates were provided through the courtesy of Miss The $o$-nitro and $p$-nitrophenyl $\beta$-glucoside tetraacetates were provided through
Montgomery and Doctors Richtmyer and Hudson, of the National Institute of Health.

${ }^{6}$ The numbers in parentheses refer to the compounds in table 1 . The sources of most of the optical-rotation data are given in the previous publication, W. W. Pigman and H. S. Isbell, J. Research NBS 27, 9 (1941) RP1399. In some cases more recent values from the following references have been used, $\mathrm{E}$. Montgomery, N. K. Richtmyer and C. S. Hudson, J. Am. Chem. Soc. 64,690 (1942); W. W. Pigman and N. K. Richtmyer, J. Am. Chem. Soc 64, 369 (1942); also N. K. Richtmyer, J. Am. Chem. Soc. 56, 1633 (1934). A number of the compounds are new ones described in the experimental part of this paper. Although the $m$-nitrophenyl $\beta$ glucoside and its tetraacetate have been previously prepared, the rotations given in table 1 were measured during the present investigation.

7 E. Glaser and W. Wulwek, Biochem. Z. 145, 514 (1924).

8 E. Montgomery, N. K. Richtmyer, and C. S. Hudson, J. Am. Chem. Soc. 64, 690 (1942).
} 
Free glucosides in water $(\lambda=589 \mathrm{~m} \mu)$
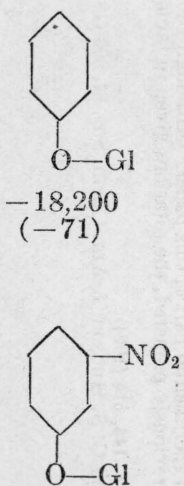

$-26,800$

$(-89)$
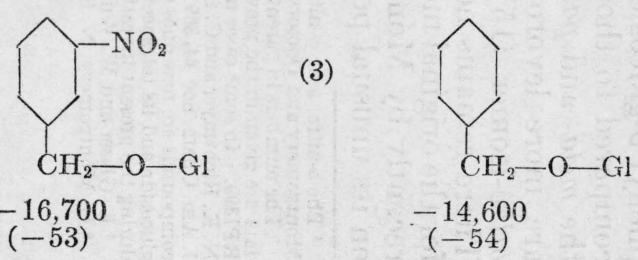

$-16,700$

$(-53)$
(3)

$$
-31,000
$$$$
(-103)
$$

(1)

(2)

$$
\begin{aligned}
& -14,600 \\
& (-54)
\end{aligned}
$$

(5)

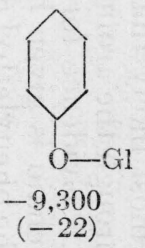

(6)

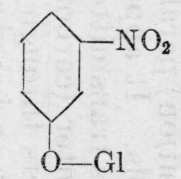

$-17,400$

(7)

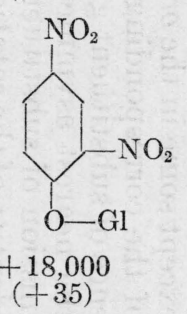

(10)

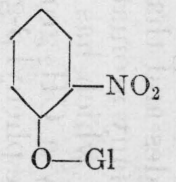

$+21,100$

(11)

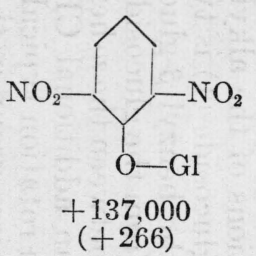

(9)

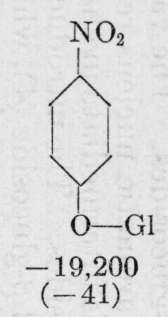

Acetates in chloroform $(\lambda=589 \mathrm{~m} \mu)$
(14)

(15)

(16) 


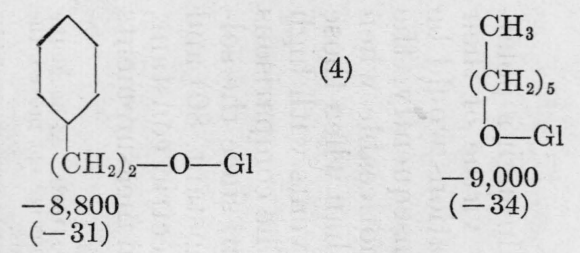

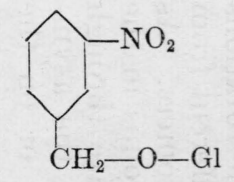

$-20,300$

$(-42)$

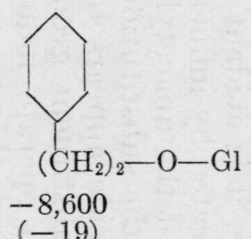

(12)

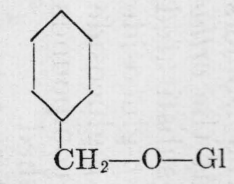

(17)

(13)

$$
\begin{gathered}
\mathrm{CH}_{3} \\
\left(\mathrm{CH}_{2}\right)_{5} \\
\mathrm{O}-\mathrm{Gl} \\
-8,600 \\
(-20)
\end{gathered}
$$


Only very few $\beta$-glucoside tetraacetates have positive rotations, and apparently all known unacetylated $\beta$-glucosides are levorotatory. In addition to the $o$-nitrophenyl $\beta$-glucoside tetraacetate, the other previously known dextrorotatory compounds are the ortho-substituted chloro-, bromo-, and iodo-methylphenyl $\beta$-glucoside tetraacetates. ${ }^{9}$ Because the effect appears to be limited to certain ortho isomers (compare compounds 10,14, and 15), it was believed that the ortho effect might be accentuated in the corresponding di-ortho-substituted compounds. For this reason, the $0, o^{\prime}$-dinitrophenyl $\beta$-glucoside tetraacetate (16) and the isomeric $o, p$-dinitrophenyl $\beta$-glucoside tetraacetate (11) were prepared. Deacetylation of these compounds without removal of the aglycon groups was not accomplished.

Both of the acetylated dinitrophenyl $\beta$-glucosides are dextrorotatory, and the di-ortho-isomer is more dextrorotatory than the known acetylated $\alpha$-glucosides. Thus, $o$-nitrophenyl $\alpha$-glucoside tetraacetate ${ }^{10}$ has a rotation of $[\alpha]_{D}^{20}=+167\left(\mathrm{CHCl}_{3}\right)$, and the $0, o^{\prime}$-dinitrophenyl $\beta$-glucoside tetraacetate has $[\alpha]_{D}^{20}=+266\left(\mathrm{CHCl}_{3}\right)$.

From the comparison made above, it is evident that the rotations of the acetylated $\beta$-glucosides are affected by influences different from those mainly operative in the case of the unacetylated isomers. As previously mentioned, the effect of the substitution of groups in the aromatic nucleus of phenyl $\beta$-glucoside appears to operate through the chain of atoms between the substituent group and the asymmetric center. It would appear to operate inductively or on the resonance of the benzene ring. ${ }^{11}$ Since this type of influence is not prominent for the acetylated derivatives, it is more probable for these compounds that the substituent groups operate through space by virtue of their electrostatic charge or simply by steric effects of the type observed for diphenyl derivatives. The remainder of this paper will be devoted to a discussion of experiments which were carried out for the elucidation of the exceptional influence of the ortho groups.

\section{NATURE OF THE "ORTHO EFFECT" OPERATIVE IN THE CASE OF THE ACETYLATED PHENYL $\beta$-GLUCO- SIDES}

\section{SOLVENT EFFECT}

If groups in the ortho-position exert their influence through a polarization of the asymmetric center at carbon 1 and by virtue of their electrostatic charge, it might be expected that the rotations would be strongly affected by the nature of the solvent. Consequently, the influence of the ortho groups should be much more noticeable when solvents with small dielectric constants are employed than when those with high dielectric constants are used; that is, the solvents with high dielectric strengths should be the best "insulators." The comparisons made in the preceding section support this explanation, since the solvent for the free glucosides is water (high dielectric constant, 80) and for the acetylated derivatives is chloroform (low dielectric constant, 5). Hence, it seemed desirable to carry out the rotation measurements

\footnotetext{
9 A. Kunz, J. Am. Chem. Soc. 48, 262 (1926).

10 E. Montgomery, N. K. Richtmyer, and C. S. Hudson, J. Am. Chem. Soc. 64, 690 (1942). Although the structures of these compounds and the configuration of the anomeric carbon atoms are not proved, the method of synthesis makes it probable that all are pyranosides with $\beta$-configurations.

11 A number of summaries of the general types of influences exerted by substituent groups are available. See, for example: A. E. Remick, Electronic Interpretations of Organic Chemistry (John Wiley \& Sons, Inc., New York, N. Y. 1943).
} 
of the unsubstituted and the acetylated glucosides in the same solvent.

In table 2 are reported the results of measurements of the specific rotation of the $o$-nitrophenyl $\beta$-glucoside and its tetraacetate in a number of different solvents. Two solvents, acetic acid and dioxane, were employed for both the compounds. In these solvents, it will be noted that the rotation of the unacetylated compound remains levorotatory and the tetraacetate remains positive.

TABLE 2.-Effect of solvent on rotation

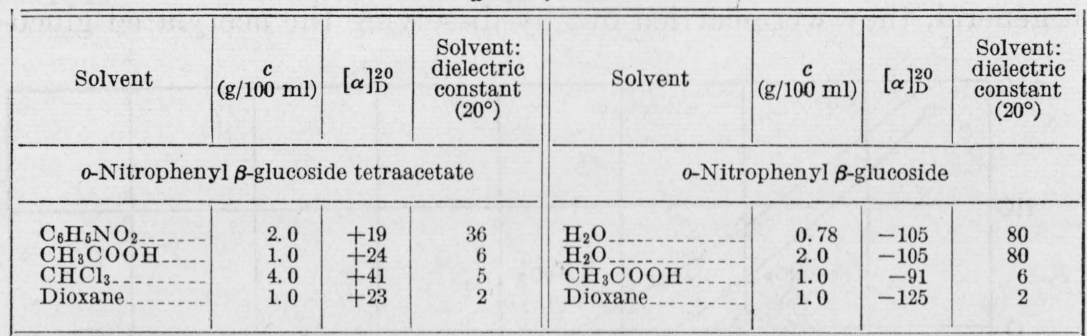

Since acetic acid and dioxane have low dielectric strengths, the polarization influence of the ortho group should be much more pronounced for the acetic acid and dioxane solutions of the unsubstituted $o$-nithrophenyl $\beta$-glucoside than for aqueous solutions; as a result, the rotations in these solvents should be less levorotatory and possibly even be dextrorotatory as for the acetylated derivatives. Similarly, the rotations of the acetylated derivatives would be expected to be more levorotatory in the solvents of higher dielectric strength (i. e., nitrobenzene).

Actually, as shown in table 2, the rotations observed in the various solvents do not agree with these predictions. It is believed, then, that the anomalous rotation of the $o$-substituted derivatives of the acetylated $\beta$-glucosides is not due primarily to a polarization of the asymmetric centers by the groups in the ortho position.

\section{TEMPERATURE INFLUENCE}

Another explanation for the differences between the rotations of the acetylated and the unacetylated glucosides and in particular for the anomalous rotations of the acetylated ortho-substituted phenyl $\beta$-glucosides might be that esterification of the hydroxyl groups by the bulky acetyl groups would allow interaction between the acetyl and the aglycon groups. Such interaction might take the form of weak bonds between these groups, or it might operate through steric hindrance to free rotation of the aglycon group about the glucosidic linkage. Examination of models of the acetylated $\beta$-glucosides shows that interaction is very probable and should be accentuated by the presence of bulky groups in the ortho position.

It has been emphasized by earlier workers ${ }^{12}$ that interactions between the various groups and solvent effects should decrease as the temperatue is increased and that measurements of the optical rotation at high temperatures tend to minimize these influences.

\footnotetext{
12 K. L. Wolf, Trans. Faraday Soc. 26, 315, 350 (1930); T. M. Lowry, Optical Rotatory Power, p. 349 and 353; Longmans, Green \& Co.. New York, N. Y., 1935. See also discussion by W. Kauzmann, J. Am. Chem. Soc. 64, 1626 (1942).
} 
At the higher temperatures, the vibrational energy of the molecules is greater and tends to disrupt weak bonds between groups in the molecule. Hence, measurements of the influence of temperature on the optical rotation should be of value in interpreting the influence of the structures of the aglycon groups of the acetylated $\beta$-glucosides on the optical rotations. For this reason, the optical rotations of a number of acetylated $\beta$-glucosides in nitrobenze solutions were measured at temperatures from $20^{\circ}$ to $150^{\circ} \mathrm{C}$. The details of these measurements are given in the experimental part of this paper. In general, they were carried out by dissolving the acetylated gluco-

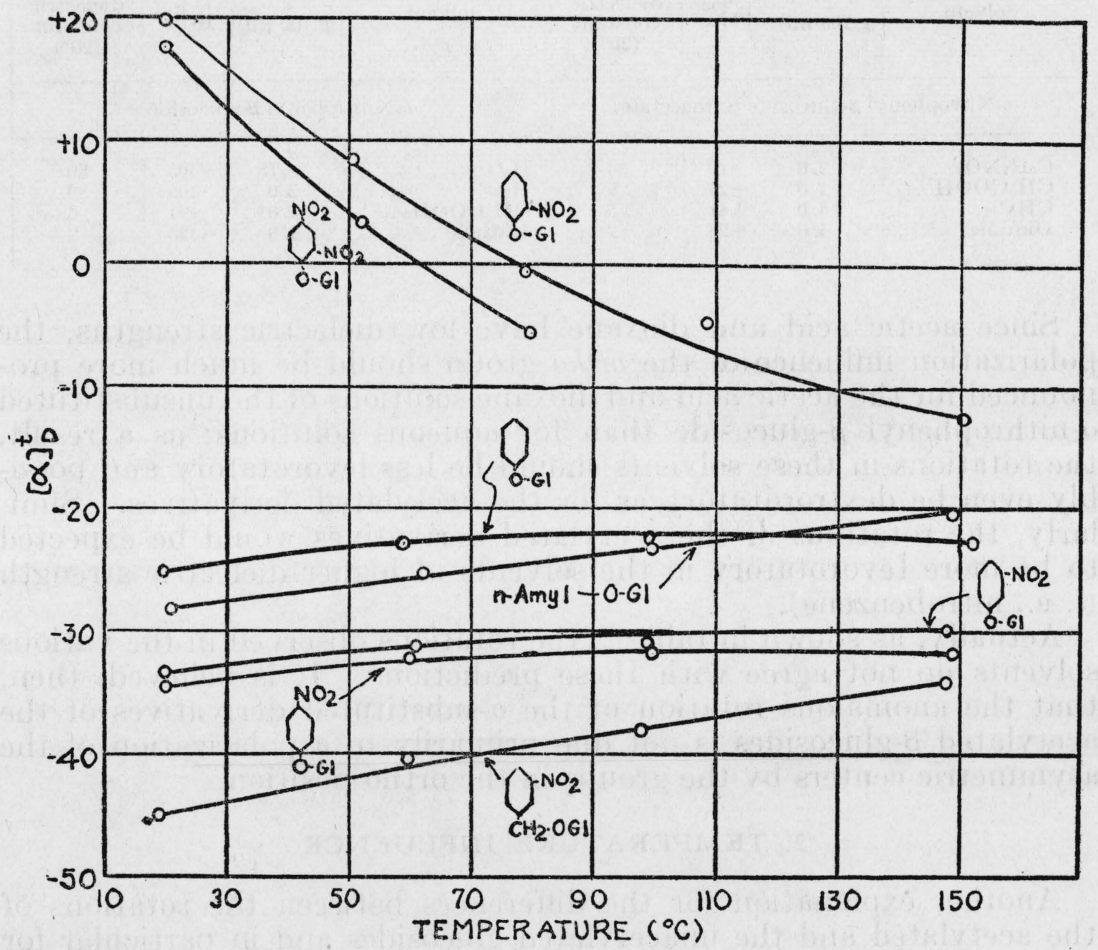

FIGURE 1.-Influence of temperature on rotation of some $\beta$-glucosides.

sides in nitrobenzene at room temperature and then by heating the solution. At various predetermined values, the temperature was held constant, and the optical rotation was measured. After the measurements at the highest temperature had been made, the solutions were cooled to $20^{\circ}$ and reread in order to determine whether decomposition or evaporation had taken place. The observed rotations were corrected for the change in density of the solvent with temperature.

The influence of temperature on the specific rotations of several acetylated $\beta$-glucosides is illustrated in figure 1 . The most noteworthy feature is the change of the sign of rotation of the $o$-nitrophenyl and the $o, p$-dinitrophenyl $\beta$-glucoside tetraacetates as the temperature increases. From the general direction of the curves it appears that 
at sufficiently high temperatures the rotation of the 0 -isomer approaches those of the meta- and para-isomers not only in sign but also in absolute value. It is believed that these results provide strong evidence that the unusual positive optical rotations of certain of the ortho-substituted phenyl $\beta$-glucoside tetraacetates ${ }^{13}$ are due to steric interactions between the groups in the ortho-position and groups attached to the asymmetric centers.

It appears that there is considerable interaction between the aglycons and the asymmetric centers of the $n$-hexyl and the $m$-nitrobenzyl derivatives, for the rotation of these compounds varies considerably as the temperature changes. At $150^{\circ}$, the rotation of the $n$-hexyl derivative becomes less negative than that of the phenyl derivative. It would seem that at the higher temperatures the predominating influence of steric effects is replaced by inductive and resonance influences of the same nature as those previously noted for the unacetylated glucosides.

The influence of temperature on optical rotation has been studied by a number of workers. However, instances of a reversal in sign as result of temperature changes are rather rare. Solutions of invert sugar ${ }^{14}$ show a reversal in sign of rotation as the temperature is raised, but this example is not comparable with the results of the present investigation, since solutions of invert sugar contain a number of different substances. The inversion of rotation noted for solutions of tartaric acid (see footnote 14) malic acid and sodium malate ${ }^{15}$ seems more likely to be of the same nature as that for the 0 -nitrophenyl $\beta$-glucoside tetraacetate.

\section{COMPARISON OF THE ROTATIONS OF THE PHENYL GLUCOSIDES AND OF THEIR TETRAACETATES}

In the previous publication, ${ }^{16}$ the partial rotations of carbon $1(A)$ and of the sum of the other active carbons $(B)$ of the glucosides and their tetraacetates were calculated by use of the isorotation rules of Hudson. ${ }^{17}$ Since then, Montgomery, Richtmyer, and Hudson ${ }^{18}$ have prepared the $o$-nitrophenyl $\alpha$-glucoside and its tetraacetate, and in the present paper the meta-isomers are described. From the rotations of these compounds, the $A$ and $B$ values for two more pairs of glucosides and their acetates can be calculated, since the rotations of corresponding $\beta$-glucosides have been described previously. In table 3 are listed the $2 A$ and $2 B$ values for all of the known pairs of substituted-phenyl glucosides and the tetraacetates.

The $2 A$ and $2 B$ values for the 0 - and m-nitrophenyl glucosides and for the acetylated meta-derivative agree well with the values previously obtained for the aromatic $\beta$-glucosides. As was also pointed out by Montgomery, Richtmyer, and Hudson, the $2 B$ value for the acetylated ortho-isomers is exceptionally large; on the other hand, the $2 A$ value

\footnotetext{
13 The optical rotation of the $0, p$-dinithropenyl $\beta$-glucoside tetraacetate could not be measured at temperatures exceeding $80^{\circ} \mathrm{C}$ because decomposition into unknown products takes place above this temperature. The $0,0^{\prime}$-isomer was even more unstable and no measurements are reported. It should also be noted that for the other compounds there was no evidence of mutarotation, since no change of rotation could be observed during the period at the fixed temperatures.

14 H. Landolt, Ber. deut. Chem. Ges. 13, 2329 (1880).

${ }_{15} \mathrm{~T}$. Thomsen, Ber. deut. Chem. Ges. 15, 441 (1882).

16 W. W. Pigman and H. S. Isbell, J. Research NBS 27, 9 (1941) RP1399

17 C. S. Hudson, BS Sci. Pap. 21, 241 (1926) S533; Rapports sur les Hydrates de Carbone, p. 59 (10th Conference of the International Union of Chemistry, Liege, 1930).

18 E. Montgomery, N. K. Richtmyer, and C. S. Hudson, J. Am. Chem. Soc. 64, 690 (1942).
} 
is much smaller than that for the aromatic glucosides and is close to that for the aliphatic glucosides (the $2 A$ value for the acetylated $n$-hexyl glucoside is 59,000). In view of the results obtained in the present investigation and discussed above, the exceptional rotations of the acetylated ortho-isomers most probably are to be ascribed to interaction between the groups in the ortho-position and the groups attached to carbons $2,3,4$, or 5 .

TABLE 3.-Sums and differences of molecular rotations of alpha and beta pairs of substituted-phenyl glucosides and tetraacetates ${ }^{\text {a }}$

\begin{tabular}{|c|c|c|c|c|}
\hline \multirow{3}{*}{ D-glucosides } & \multicolumn{2}{|c|}{ Not Acetylated } & \multicolumn{2}{|c|}{ Acetylated } \\
\hline & \multicolumn{2}{|c|}{$\begin{array}{l}\text { Rotations measured } \\
\text { in } \mathrm{H}_{2} \mathrm{O} \text { for } \mathrm{D} \text { line }\end{array}$} & \multicolumn{2}{|c|}{$\begin{array}{l}\text { Rotations measured } \\
\text { in } \mathrm{CHCl}_{3} \text { for } \mathrm{D} \text { line }\end{array}$} \\
\hline & $\begin{array}{c}\text { Difference, } \\
2 A\end{array}$ & Sum, $2 B$ & $\begin{array}{c}\text { Difference, } \\
2 A\end{array}$ & Sum, $2 B$ \\
\hline \multirow{4}{*}{$\begin{array}{l}\text { Phenyl } \\
p \text {-Aminophenyl } \\
p \text {-Hydroxyphenyl } \\
p \text {-Benzoyloxyphenyl } \\
p \text {-Nitrophenyl } \\
m \text {-Nitrophenyl- } \\
o \text {-Nitrophenyl }\end{array}$} & \multirow{2}{*}{$\begin{array}{r}67,800 \\
-70,300 \\
65,900\end{array}$} & \multirow{2}{*}{$\begin{array}{r}31,400 \\
-35,000 \\
31,300\end{array}$} & 80,600 & 62,000 \\
\hline & & & \multirow{3}{*}{$\begin{array}{r}82,900 \\
113,100 \\
98,300 \\
57,300\end{array}$} & \multirow{3}{*}{$\begin{array}{l}67,100 \\
74,700 \\
64,100 \\
99,500\end{array}$} \\
\hline & \multirow[t]{2}{*}{$\begin{array}{l}95,800 \\
84,050 \\
94,000\end{array}$} & $\begin{array}{l}33,800 \\
30,400 \\
30,100\end{array}$ & & \\
\hline & & Avg 32,000 & & \\
\hline
\end{tabular}

: For origin of data, see footnote 6, p. 131

b Incorrectly termed " $p$-Benzoylphenyl" in the first publication.

c One rotation measured in methyl alcohol.

\section{MEASUREMENT OF THE ROTATORY DISPERSIONS OF SOME AROMATIC GLUCOSIDES AND THEIR TETRA- ACETATES}

The variation of optical rotation with the wavelength of the light source used for the measurements (called rotatory dispersion) frequently may be expressed by a simple form of the Drude equation:

$$
\alpha=\frac{A}{\lambda^{2}-\lambda_{0}^{2}}
$$

where $\alpha$ is the rotation at the wavelength $\lambda, A$ is the so-called rotation constant, and $\lambda_{0}^{2}$ is the dispersion constant. Sometimes the addition of a second term, $B / \lambda^{2}$, is necessary in order that the experimental data be satisfied completely. According to Lowry, ${ }^{19}$ rotatory dispersions which fit the one-term equation are to be described as "simple rotatory dispersions"; those which require another term in the equation are to be known as "complex rotatory dispersions." A simple graphical method for testing the applicability of the equation 1 to rotatory dispersion data consists in plotting $1 / \alpha \mathrm{vs} . \lambda^{2}$. If a straight line results, the dispersion is of the "simple" type.

According to equation 1 , the rotation becomes infinite when $\lambda=\lambda_{0}$. The wavelength $\lambda_{0}$ sometimes is assumed to represent an optically active absorption band, which lies in the ultraviolet region for colorless substances, such as the sugars and their derivatives. The determination of the position of this absorption band is a matter of interest, since it may provide some information concerning the nature of the groups

${ }_{10}$ T. M, Lowry, Optical Rotatory Power, p. 123, (Longmans, Green, \& Co., London, 1935), 
that are responsible for the absorption and probably also for the optical rotation in the visible region. For this reason it appeared desirable to measure the rotatory dispersion of some of the compounds considered in the present paper.

TABLE 4.-Equations for dispersions $\left(T=18^{\circ}\right.$ to $\left.21^{\circ} \mathrm{C}\right)$

\begin{tabular}{|c|c|c|c|c|}
\hline Compound & Solvent & A & $\begin{array}{c}\lambda_{0}^{2} \\
\text { ( } \lambda \text { in mi- } \\
\text { crons })\end{array}$ & $\begin{array}{c}\lambda_{0} \\
\text { (angstrom } \\
\text { units) }\end{array}$ \\
\hline $\begin{array}{l}\text { Phenyl } \beta \text {-glucoside tetraacetate } \\
m \text {-Nitrophenyl } \beta \text {-glucoside tetraacetate-... } \\
p \text {-Nitrophenyl } \beta \text {-glucoside tetracetate. } \\
m \text {-Nitrobenzyl } \beta \text {-glucoside tetraacetate } \\
o, o^{\prime} \text {-Dinitrophenyl } \beta \text {-glucoside tetraacetate.. }\end{array}$ & $\begin{array}{l}\mathrm{CHCl}_{3} \\
\mathrm{CHCl}_{3} \\
\mathrm{CHCl}_{3} \\
\mathrm{CHCl}_{3} \\
\mathrm{CHCl} \mathrm{Cl}_{3}\end{array}$ & $\begin{array}{r}-6.2 \\
-10.2 \\
-9.6 \\
-12.6 \\
+55.9\end{array}$ & $\begin{array}{l}0.066 \\
.072 \\
.089 \\
.046 \\
.137\end{array}$ & $\begin{array}{l}2570 \\
2680 \\
3150 \\
2140 \\
3700\end{array}$ \\
\hline 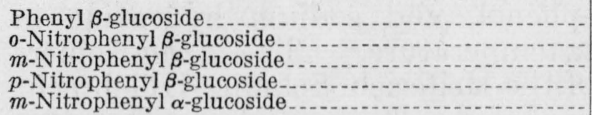 & $\begin{array}{l}\mathrm{H}_{2} \mathrm{O} \\
\mathrm{H}_{2} \mathrm{O} \\
\mathrm{H}_{2} \mathrm{O} \\
\mathrm{H}_{2} \mathrm{O} \\
\mathrm{H}_{2} \mathrm{O}\end{array}$ & $\begin{array}{l}-21.9 \\
-25.8 \\
-25.6 \\
-28.3 \\
+56.6\end{array}$ & $\begin{array}{l}.050 \\
.000 \\
.058 \\
.073 \\
.048\end{array}$ & $\begin{array}{l}2240 \\
3160 \\
2420 \\
2700 \\
2190\end{array}$ \\
\hline
\end{tabular}

Some measurements previously reported for alkyl glucosides

Methyl $\beta$-glucoside tetraacetate ${ }^{\mathrm{a}}$

Methyl $\beta$-glucoside b

Methyl $\alpha$-glucoside b

s T. L. Harris, E. L. Hirst, and C. E. Wood, J. Chem. Soc. (1932) 2108.

b N. A. Sörensen and B. Trumpy, Z. physik. Chem. [B] 28, 135 (1935).

In table 4 are summarized the rotatory dispersion measurements that are of the simple type and that fit the one-term Drude equation 1. The measurements were carried out by use of a Schmidt and Haensch precision polarimeter; they were made at five wave lengths: 436, about 512, 589, and about $645 \mathrm{~m} \mu$. The details are given in the experimental part of this paper. Data also are given in the experimental part for the $o$-nitrophenyl and the $o, p$-dinitrophenyl $\beta$ glucoside tetraacetates; these data could not be fitted to the simple form of the Drude equation and are of the "complex" type.

It is of interest that two of the ortho-substituted derivatives have "complex" rotatory dispersions. These same acetylated derivatives are the compounds that exhibit the anomalous positive rotations, as previously mentioned. Peculiarly enough, the $0,0^{\prime}$-derivative, for which the effect might be expected to be greatly accentuated, exhibits a simple dispersion. The optical rotation of the acetylated orthosubstituted derivatives could not be measured by use of a saccharimeter and white light because of the difference in color of the two sides of the optical field. This difference in color undoubtedly arises from the disparity in the dispersion of quartz and of the acetylated ortho-substituted derivatives.

In table 4 , the values of the dispersion constant $\left(\lambda_{0}^{2}\right)$ are given. As previously mentioned, $\lambda_{0}$ may represent optically active absorption bands. It is of interest then that for the aromatic glucosides the position of these bands is closer to the visible region than for the alkyl glucosides and that the introduction of nitro groups into the aromatic nucleus produces a shift in the position of the bands still further toward the visible region. These values might be inter- 
preted as indicating that the groups responsible for the absorption are alkyl groups (for the alkyl glucosides), the aromatic nucleus (for the phenyl glucosides), and the nitro or nitrophenyl groups (for the nitrophenyl glucosides). It is well known that absorption of ultraviolet light occurs for such groups in the approximate regions represented by the values of $\lambda_{0}$. The absorption bands $\left(\lambda_{0}\right)$ for the acetylated derivatives, as a rule, lie closer to the visible region than those of the unacetylated derivatives. It would appear that the acetyl groups may have some influence on the position of the band; however, there is no evidence that the shift in position may not be a solvent effect.

\section{EXPERIMENTAL PROCEDURE}

\section{PREPARATION OF GLUCOSIDES}

(a) SUBSTITUTED-PHENYL D-GLUCOSIDES

The new beta-isomers were prepared by reacting tetraacetylglucosyl bromide, the substituted-phenol, and sodium hydroxide in aqueous acetone solution at room temperature. ${ }^{20}$ The alpha-isomers were obtained by a modification of the Helferich, Schmitz-Hillebrecht method, as described for ' $o$-nitrophenyl $\alpha$-D-glucoside. ${ }^{21}$ Deacetylation of the tetraacetates was accomplished by the action of small quantities of barium methylate in boiling methanol. ${ }^{22}$ The successful deacetylation of the dinitrophenyl $\beta$-D-glucosides has not yet been achieved; under all of the conditions employed, the aglycon group was removed with the acetyl groups.

$m$-Nitrophenyl $\alpha$-D-glucoside and tetraacetate.-The product obtained by fusion of pentaacetylglucose and $m$-nitrophenol with zinc chloride did not crystallize even when purified by fractional extraction. After deacetylation, a sirupy product was obtained. The material, which was soluble in isopropyl alcohol but which was not precipitated from the alcohol solution by the addition of absolute ether, crystallized, giving a small yield of a mixture of the alpha- and beta-isomers. (From $30 \mathrm{~g}$ of pentaacetylglucose, $3 \mathrm{~g}$ of the mixture was obtained, which was principally the alpha-isomer). The alpha-isomer was obtained in pure condition by crystallization from water until the rotation remained constant. The substance crystallizes from water apparently in the anhydrous condition as long slender needles. It was dried in high vacuum at $100^{\circ} \mathrm{C}$ before the physical properties were determined. It melts at $172^{\circ}$ to $175^{\circ} \mathrm{C}$ (cor.); at $20^{\circ} \mathrm{C}, 1.6 \mathrm{~g}$ dissolves in $100 \mathrm{ml}$ of aqueous solution. $[\alpha]_{\mathrm{p}}^{20}=+189$ (c, 1.6; water). Analysis: Calculated for $\mathrm{C}_{13} \mathrm{H}_{17} \mathrm{O}_{8} \mathrm{~N}$ : N, 4.65; Found: N, 4.60.

Tetraacetate.-The glucoside was acetylated with sodium acetate and acetic anhydride and recrystallized several times from ethyl alcohol. It crystallizes as rectangular prisms. The pure material has a melting point of $104.2^{\circ}$ to $104.4^{\circ} \mathrm{C}$ (cor.); $[\alpha]_{0}^{20}=+173(c, 2.4$; $\mathrm{CHCl}_{3}$ ). Analysis: Calculated for $\mathrm{C}_{20} \mathrm{H}_{23} \mathrm{O}_{12} \mathrm{~N}: \mathrm{N}, 2.98$; Found: N, 3.05 .

$o, p$-Dinitrophenyl $\beta$-D-glucoside tetraacetate.-About $4.5 \mathrm{~g}$ of the tetraacetate was obtained from $34 \mathrm{~g}$ of tetraacetylglucosyl bromide by use of the directions of Glaser and Wulwek. Several recrystallizations from ethyl alcohol or acetone gave a colorless product crystallizing

${ }_{20}$ The original method is a modification of the Michael synthesis (Am. Chem. J. 1, 305 (1879), but the specific directions given by E. Glaser and W. Wulwek, Biochem. Z. 145, 514 (1924) were followed.

21 E. M. Montgomery, N. K. Richtmyer, and C. S. Hudson, J. Am. Chem. Soc. 64, 690 (1942); B. Helferich and E. Schmitz-Hillebrecht, Ber. deut. Chem. Ges. 66, 378 (1933).

${ }^{22}$ H. S. Isbell, BS J. Research 5, 1185 (1930) RP253. G. Zemplén and E. Pacsu, Ber. deut. Chem. Ges. 62, 1613 (1929). 
as elongated prisms and melting at $173^{\circ}$ to $177^{\circ} \mathrm{C}$ (cor.); $\left[\alpha\left[_{D}^{20}=+34.5\right.\right.$ $\left(c, 4 ; \mathrm{CHCl}_{3}\right)$. When the rotation is read in a saccharimeter an appreciable difference in the tint of the two sides of the field is observed. However, no significant difference was observed in values measured with the saccharimeter from those obtained by use of a polarimeter. Analysis: Calculated for $\mathrm{C}_{20} \mathrm{H}_{22} \mathrm{O}_{14} \mathrm{~N}_{2}: \mathrm{N}, 5.45$; Found: $\mathrm{N}, 5.59$.

$o, 0^{\prime}$-Dinitrophenyl $\beta$-d-glucoside tetraacetate.-From $34 \mathrm{~g}$ of tetraacetylglycosyl bromide and by the use of the same proportions of reagents as described by Glaser and Wulwek, about $20 \mathrm{~g}$ of the acetylated glucoside was obtained. After a number of recrystallizations from acetone, from which the compound crystallizes as truncated prisms, it was found to melt at $175.5^{\circ}$ to $176.0^{\circ} \mathrm{C}$ (cor.) apparently with some decomposition as the liquid has a greenish color. The compound dissolves with difficulty at room temperature in many common organic solvents, such as alcohols and acetone, and is much less soluble in chloroform than most acetylated glycosides. $[\alpha]_{\mathrm{p}}^{19}=+266\left(c, 4 ; \mathrm{CHCl}_{3}\right)$. This rotation must be measured in a polarimeter because of the great difference in the tint of the two halves of the field when a saccharimeter is employed. Analysis: Calculated for $\mathrm{C}_{20} \mathrm{H}_{22} \mathrm{O}_{14} \mathrm{~N}_{2}: \mathrm{N}, 5.45$; Found: N, 5.50.

$m$-Nitrobenzyl $\beta$-D-glucoside and tetraacetate.-A modification ${ }^{23}$ of the Koenigs-Knorr systhesis when applied to $41 \mathrm{~g}$ of tetraacetylglucosyl bromide and $37 \mathrm{~g}$ of $m$-nitrobenzyl alcohol yielded $23 \mathrm{~g}$ of $m$-nitrobenzyl $\beta$-glucoside tetraacetate. After three recrystallizations from ethyl alcohol, the substance melted at $120.0^{\circ}$ to $120.5^{\circ} \mathrm{C}$ (cor.) and had a specific rotation $[\alpha]_{D}^{20}=-42.1\left(c, 4.2 ; \mathrm{CHCl}_{3}\right)$. Analysis: Calculated for $\mathrm{C}_{21} \mathrm{H}_{25} \mathrm{O}_{10} \mathrm{~N}$ : N, 2.90; Found: N, 2.81 .

Free glucoside.-Catalytic deacetylation led to the free glucoside which, after purification and subjection to a high vacuum at a temperature of $100^{\circ} \mathrm{C}$, melted at $158^{\circ}$ to $159^{\circ} \mathrm{C}$ (cor.). It crystallizes from methanol as squares chunky prisms. The anhydrous material rotates, $[\alpha]_{0}^{20}=-52.8(c, 2$; water). These values agree with those of $157^{\circ}$ to $158^{\circ} \mathrm{C}$ and -52.6 previously reported for this compound by Bourquelot and Ludwig, ${ }^{24}$ who obtained it by enzymic synthesis. Analysis: Calculated for $\mathrm{C}_{13} \mathrm{H}_{17} \mathrm{O}_{8} \mathrm{~N}$ : N, 4.44; Found: N, 4.36.

\section{OPTICAL-ROTATION MEASUREMENTS}

(a) INFLUENCE OF TEMPERATURE

For the measurement of the influence of temperature on the optical rotation, a thermostated air bath (12 in. wide by 15 in. deep by 17 in. high) was constructed. The bath consisted of a wooden box lined with asbestos sheets and equipped with electric heaters (two 1,320watt heaters in parallel) controlled by a bimetallic thermoregulator and relay. The air was kept in circulation with a motor-driven fan. The box was mounted between the nicol prisms of a Bates saccharimeter after removal of the trough. A trough was placed in the box in such position that it would hold a polariscope tube along the optic axis of the instrument. At the ends of the trough, holes were drilled in the sides of the box. Each hole was covered with two glass plates separated by an air space. (Polariscopic cover glasses were found particularly suitable, one on the inside and one on the outside of each hole in the box. They are easy to fit and are optically clear and inactive.)

${ }^{23}$ W. W. Pigman and N. K. Richtmyer, J. Am. Chem. Soc. 64, 369 (1942).

24 E. Bourquelot and A. Ludwig, Compt. rend. 158, 1037 (1914). 
The tube used to contain the solution consisted of a jacketed, 2-dm brass tube with tublature in which a thermometer could be inserted.

For the measurements, a weighed quantity of the acetylated glucoside was made up to volume at $20^{\circ}$ with nitrobenzene. The optical rotation was measured at $20^{\circ} \mathrm{C}$. The tube containing the solution then was placed in the air bath, and the rotations were read at intervals up to $150^{\circ} \mathrm{C}$. At each of the temperatures selected for the measurements, the thermostatic control was placed in operation and the temperature was allowed to attain constancy. (About $30 \mathrm{~min}$. usually was necessary.) The temperature inside the tube and inside the box was recorded for each optical-rotation measurement. Temperature constancy of about $\pm 1^{\circ} \mathrm{C}$ was achieved. After the temperature measurements at $150^{\circ} \mathrm{C}$ had been completed, the solution was allowed to cool and was reread to $20^{\circ} \mathrm{C}$. As noted in a previous section, several of the glucosides were unstable under these conditions, and the final rotations were different from those initially measured.

In order to translate the observed optical rotations into specific rotations, it is necessary to correct for the changes in the density of the solutions with temperature. Instead of using the density of the solutions, the known density of the solvent (nitrobenzene) was employed. It is believed that these values are sufficiently close to those of the solutions that no appreciable error is introduced. The density values employed are those measured by Jaeger. ${ }^{25}$ Calculations of the expansion of brass over the temperature range $20^{\circ}$ to $150^{\circ} \mathrm{C}$ showed that the expansion of the tube was not enough to influence the results. The values obtained are recorded in table 5 .

TABLE 5.-Variation of optical rotations of acetylated glucosides in nitrobenzene solution with temperature

\begin{tabular}{|c|c|c|c|c|c|c|c|}
\hline Temperature & $c$ & ${ }^{\circ} \mathrm{S}$ & {$[\alpha] \stackrel{t}{\mathrm{D}}$} & Temperature & $c$ & ${ }^{\circ} \mathrm{S}$ & {$[\alpha]_{\mathrm{D}}^{t}$} \\
\hline \multicolumn{4}{|c|}{ Phenyl $\beta$-glucoside tetraacetate } & \multicolumn{4}{|c|}{$m$-Nitrobenzyl $\beta$-glucoside tetraacetate } \\
\hline $\begin{array}{l}21 \\
59 \\
100 \\
152\end{array}$ & $\begin{array}{r}g / 100 m l \\
2.038\end{array}$ & $\begin{array}{l}-2.97 \\
-2.62 \\
-2.45 \\
-2.36\end{array}$ & $\begin{array}{l}-25.2 \\
-22.9 \\
-22.3 \\
-22.6\end{array}$ & 1906. & $\begin{array}{r}\mathrm{g} / 100 \mathrm{ml} \\
2.058 \\
0\end{array}$ & $\begin{array}{l}-5.34 \\
-4.65 \\
-4.23 \\
-3.60\end{array}$ & $\begin{array}{l}-44.9 \\
-40.4 \\
-38.0 \\
-34.0\end{array}$ \\
\hline \multicolumn{4}{|c|}{$p$-Nitrophenyl $\beta$-glucoside tetraacetate } & \multicolumn{4}{|c|}{$0, p$-Dininitrophenyl $\beta$-glucoside tetraacetate } \\
\hline $\begin{array}{l}20 \ldots \\
60 \ldots \\
100 \ldots \\
149 \ldots\end{array}$ & $\begin{array}{r}1.907 \\
\hdashline \\
\hdashline\end{array}$ & $\begin{array}{l}-3.80 \\
-3.43 \\
-3.25 \\
-3.09\end{array}$ & $\begin{array}{l}-34.5 \\
-32.1 \\
-31.6 \\
-31.6\end{array}$ & $\begin{array}{l}20 \\
52 \\
110 \\
(18)\end{array}$ & $\begin{array}{r}0.827 \\
\\
\hdashline\end{array}$ & $\begin{array}{r}+0.84 \\
+.16 \\
-.25 \\
(-.23) \\
(+2.34)\end{array}$ & $\begin{array}{c}+17.6 \\
+3.4 \\
-5.5 \\
(-5.2) \\
(+49)\end{array}$ \\
\hline \multicolumn{4}{|c|}{$m$-Nitrophenyl $\beta$-glucoside tetraacetate } & \multicolumn{4}{|c|}{$0,0^{1}$ Dinitrophenyl $\beta$-glucoside tetraacetate } \\
\hline $\begin{array}{l}20 .- \\
61 . \\
101 \\
150 .\end{array}$ & $\begin{array}{r}2.004 \\
\\
\hdashline\end{array}$ & $\begin{array}{l}-3.87 \\
-3.50 \\
-3.33 \\
-3.07\end{array}$ & $\begin{array}{l}-33.4 \\
-31.2 \\
-30.8 \\
-29.8\end{array}$ & $\begin{array}{l}19 \\
51 \\
79 \\
110 \\
(20)\end{array}$ & $\begin{array}{r}2.023 \\
\\
\hdashline\end{array}$ & $\begin{array}{r}+29.3 \\
+24.6 \\
+20.1 \\
(+10.1) \\
(+6.5)\end{array}$ & $\begin{array}{l}+250 \\
+215 \\
+181 \\
(+93) \\
(+56)\end{array}$ \\
\hline \multicolumn{4}{|c|}{ o-Nitrophenyl $\beta$-glucoside tetraacetate } & \multicolumn{4}{|c|}{$n$-Amyl $\beta$-glucoside tetraacetate } \\
\hline $\begin{array}{l}20 \ldots \\
51 \ldots \\
79 \\
109 \ldots \\
151_{\ldots}\end{array}$ & \begin{tabular}{r}
2.013 \\
\hdashline-1. \\
-2 \\
\end{tabular} & $\begin{array}{r}+2.31 \\
+0.96 \\
-.06 \\
-.51 \\
-1.29\end{array}$ & $\begin{array}{r}+19.9 \\
+8.5 \\
-0.5 \\
-4.7 \\
-12.5\end{array}$ & $\begin{array}{l}21 \\
62 \\
100 \\
149\end{array}$ & \begin{tabular}{r}
2.071 \\
\hdashline-1. \\
$-\ldots$
\end{tabular} & $\begin{array}{l}-3.40 \\
-2.92 \\
-2.61 \\
-2.17\end{array}$ & $\begin{array}{l}-28.4 \\
-25.2 \\
-23.3 \\
-20.4\end{array}$ \\
\hline
\end{tabular}

${ }^{25}$ F. M. Jaeger, Z. anorg. Chem. 101, 112 (1917). 


\section{(b) MEASUREMENTS OF ROTATORY DISPERSION}

The rotatory dispersions were measured by the use of a Schmidt \& Haensch precision polariscope equipped with a monochromator. A mercury-vapor lamp $(\mathrm{H}-4 ; 100 \mathrm{w}$.) provided lines at $546 \mathrm{m \mu}$ and $436 \mathrm{m \mu}$. For the 436 line, the amount of light passing through the monochromator was insufficient; therefore, the light was passed through a "monochromatic" glass filter (Corning M 440). An electric sodium lamp with bichromate filter provided a light source at $589 \mathrm{m \mu}$. Two other lines at about 510 and $640 \mathrm{~m} \mu$ were provided by the use of a tungsten lamp and the monochromator. For the latter lines, the wavelength was determined at each measurement by reading a quartz plate of known rotation; the reading obtained for the quartz plate was used to calculate the wavelength by reference to the known data for the dispersion of quartz.

Four-decimeter tubes were used, and the same solution was used for the rotation measurements at each of the selected wavelengths. The experiments were carried out in a room in which the temperature was controlled between $18^{\circ}$ and $21^{\circ} \mathrm{C}$. The data are given in table 6 and summarized in table 4.

TABLE 6.-Rotatory dispersions of glucosides and tetraacetales

\begin{tabular}{|c|c|c|c|c|c|c|c|}
\hline \multicolumn{8}{|c|}{$\beta$ - or $\alpha$-glucosides in water } \\
\hline Aglycon group & $c$ & $\lambda$ & {$[\alpha]^{180}$ to 210} & Aglycon group & $c$ & $\lambda$ & {$[\alpha]^{180}$ to $21^{\circ}$} \\
\hline $\begin{array}{l}\mathrm{C}_{6} \mathrm{H}_{5}-(\beta) \\
p-\mathrm{NO}_{2}-\mathrm{C}_{6} \mathrm{H}_{4}-(\beta) \ldots . \\
m-\mathrm{NO}_{2}-\mathrm{C}_{6} \mathrm{H}_{4}-(\alpha) \ldots\end{array}$ & $\left\{\begin{array}{c}g / 100 \mathrm{ml} \\
1.62 \\
\hdashline 1.61 \\
\hdashline 0.99 \\
\hdashline\end{array}\right.$ & $\begin{array}{l}m \mu \\
436 \\
512 \\
546 \\
589 \\
645 \\
436 \\
511 \\
546 \\
589 \\
644 \\
436 \\
511 \\
546 \\
589 \\
641\end{array}$ & $\begin{array}{r}-149 \\
-102 \\
-87 \\
-73 \\
-59 \\
-255 \\
-151 \\
-126 \\
-103 \\
-83 \\
+398 \\
+267 \\
+225 \\
+190 \\
+156\end{array}$ & $m-\mathrm{NO}_{2}-\mathrm{C}_{6} \mathrm{H}_{4}-(\beta)$ & $\left\{\begin{array}{c}g / 100 \mathrm{ml} \\
2.01 \\
\hdashline\end{array}\right.$ & $\begin{array}{l}m \mu \\
436 \\
511 \\
546 \\
589 \\
641 \\
436 \\
513 \\
546 \\
589 \\
645\end{array}$ & $\begin{array}{r}-194 \\
-126 \\
-107 \\
-89 \\
-72 \\
-280 \\
-160 \\
-130 \\
-105 \\
-81\end{array}$ \\
\hline
\end{tabular}

$\boldsymbol{\beta}$-glucoside tetraacetates in chloroform

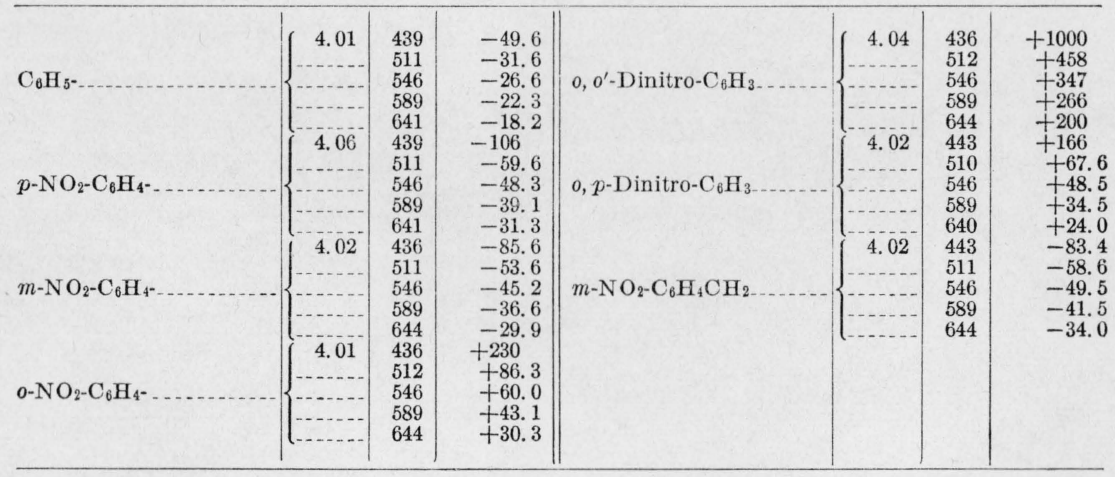


The writer expresses his appreciation for the assistance given by Paul E. Golden in the measurements of the rotatory dispersion and of the temperature influences. The aid given by Miss Mary Grace Blair in the calculations and in the preparation of the manuscript was of great help. The cooperation of Miss E. Montgomery and Doctors Richtmyer and Hudson, of the National Institute of Health, in providing certain of the compounds used in this investigation, and of Kenneth Fleischer, of this Bureau, in performing the microchemical analyses is gratefully acknowledged.

Washington, May 27, 1944. 
NATIONAL BUREAU OF STANDARDS, WASHINGTON 25, D. C.

Send me the Mathematical Tables marked X below. I enclose remittance ${ }^{1}$ to cover the cost.

\begin{tabular}{|c|c|c|c|c|}
\hline Mark X & Title of publication & $\begin{array}{l}\text { United States and } \\
\text { its possessions, } \\
\text { and countries ex- } \\
\text { tending franking } \\
\text { privilege } \\
\end{array}$ & Other countries & Imount enclosec \\
\hline 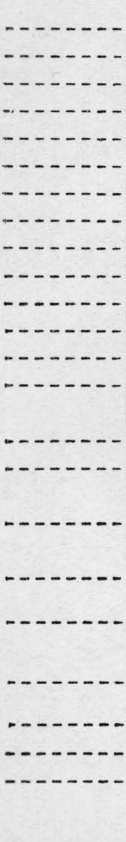 & 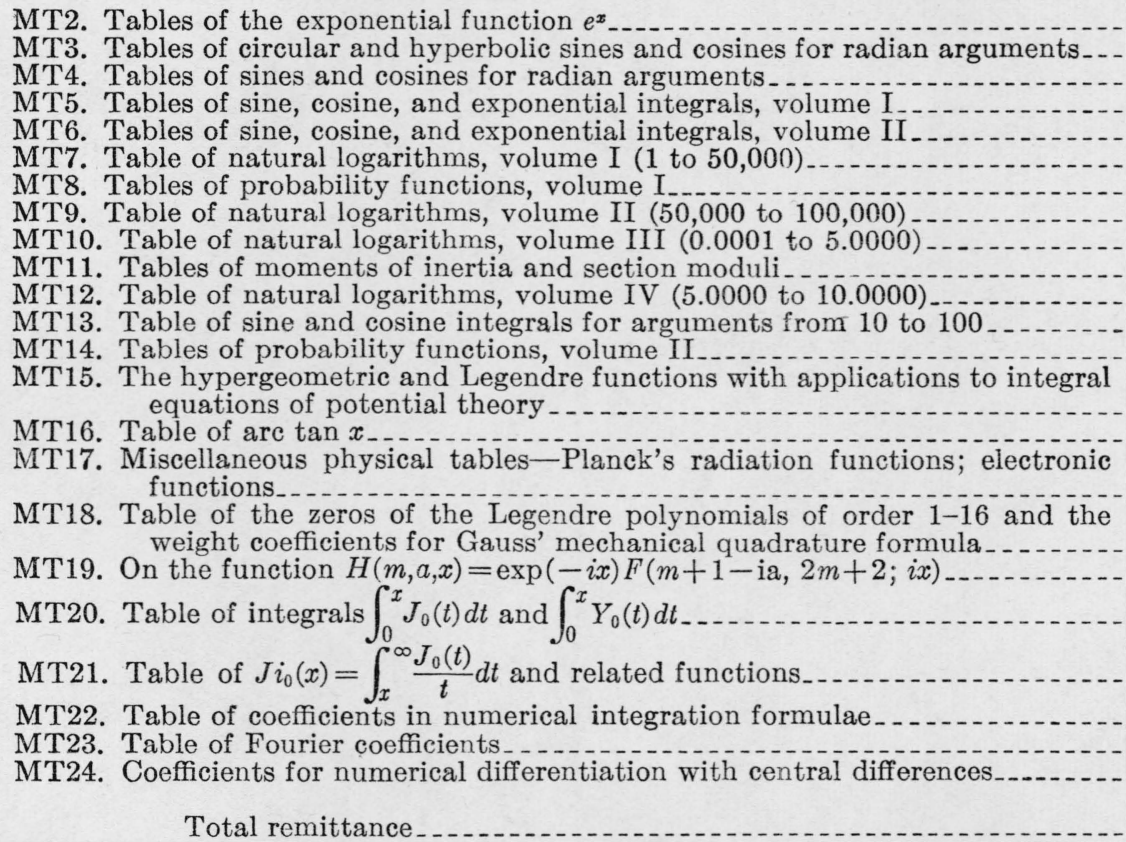 & $\begin{array}{r}\$ 2.00 \\
2.00 \\
2.00 \\
2.00 \\
2.00 \\
2.00 \\
2.00 \\
2.00 \\
2.00 \\
2.00 \\
2.00 \\
2.00 \\
2.00 \\
2.00 \\
2.00\end{array}$ & $\begin{array}{r}\$ 2.50 \\
2.50 \\
2.50 \\
2.50 \\
2.50 \\
2.50 \\
2.50 \\
2.50 \\
2.50 \\
2.50 \\
2.50 \\
2.50 \\
2.50 \\
2.50 \\
2.50 \\
1.75\end{array}$ & - \\
\hline
\end{tabular}

Remittance should be in form of post-office money order, or check, and made payable to the order of the "National Bureau of Standards" in United States currency.

Send to Number and Street. 


\section{MATHEMATICAL TABLES}

Attention is invited to a series of publications prepared by the Project for the Computation of Mathematical Tables conducted by the Federal Works Agency, Work Projects Administration for the City of New York, under the sponsorship of the National Bureau of Standards. The tables which have been made available through the National Bureau of Standards are listed below.

There is included in this list a publication on the hypergeometric and Legendre functions (MT15), prepared by the Bureau.

MT1. Table of the First Ten Powers op the Integers From 1 to 1000:

(1938) VIII + 80 pages; heavy paper cover. Out of print.

MT2. Tables of the Exponential Function $e^{x}$ :

The ranges and intervals of the argument and the number of decimal places in the entries are given below:

$\begin{array}{ccc}\text { Range of } x & \text { Interval of } x & \text { Decimals given } \\ -2.5000 \text { to } 1.0000 & 0.0001 & 18 \\ 1.0000 \text { to } 2.5000 & .0001 & 15 \\ 2.500 \text { to } 5.000 & .001 & 15 \\ 5.00 \text { to } 10.00 & .01 & 12\end{array}$

(1939) XV+535 pages; bound in buckram, $\$ 2.00$.

MT3. Tables op Circular and Hyperbolic Sines and Cosines for Radian Argumpnts:

Contains 9 decimal place values of $\sin x, \cos x, \sinh x$, and $\cosh x$ for $x$ (in radians) ranging from 0 to 2 at intervals of 0.0001

(1939) XVII + 405 pages; bound in buckram, $\$ 2.00$.

MT4. Tables of Sinfs and Cosines for Radian Arguments:

Contains 8 decimal place values of sines and cosines for radian arguments ranging from 0 to 25 at intervals of 0.001 .

(1940) XXIX + 275 pages; bound in buckram, $\$ 2.00$.

MT5. Tables or Sine, Cosine, and Exponential Integrals, Volume I:

Values of these functions to 9 places of decimals from 0 to 2 at intervals of 0.0001.

(1940) XXVI+ 444 pages; bound in buckram, $\$ 2.00$.

MT6. Tables of Sine, Cosine, and Exponential Integrals, Volume II:

Values of these functions to 9,10 , or 11 significant figures from 0 to 10 at intervals of 0.001 with auxiliary tables.

(1940) XXXVII+225 pages; bound in buckram, $\$ 2.00$.

MT7. Table of Natural Logarithms, Volume I:

Logarithms of the integers from 1 to 50,000 to 16 places of decimals.

(1941) XVIII+ 501 pages; bound in buckram, $\$ 2.00$.

MT8. Tables of Probability Functions, Volume I:

Values of these functions to 15 places of decimals from 0 to 1 at intervals of 0.0001 and from

1 to 5.6 at intervals of 0.001 .

(1941) XXVIII+302 pages; bound in buckram, $\$ 2.00$.

MT9. Table op Natural Logarithms, Volume II:

Logarithms of the integers from 50,000 to 100,000 to 16 places of decimals.

(1941) XVIII+501 pages; bound in buckram, $\$ 2.00$.

MT10. Tablr of Natural Logarithms, Volume III:

Logarithms of the decimal numbers from 0.0001 to 5.0000 , to 16 places of decimals.

(1941) XVIII+ 501 pages; bound in buckram, $\$ 2.00$.

MT11. Tables of the Moments of Inertia and Section Moduli of Ordinary Angles, Chan. nels, and Bulb Angles with Certain Plate Combinations:

(1941) XIII+197 pages; bound in green cloth. \$2.00.

MT12. Table op Natural Logarithms, Volume IV: Logarithms of the decimal numbers from 5.0000 to 10.0000 , to 16 places of decimals. (1941) XXII+ 506 pages; bound in buckram, $\$ 2.00$.

MT13. TAble of Sine and Cosine Integrals for Arguments from 10 to 100:

(1942) XXXII+185 pages; bound in buckram, $\$ 2.00$.

MT14. Tables of Probability Functions, Volume II:

Values of these functions to 15 places of decimals from 0 to 1 at intervals of 0.0001 and from

1 to 7.8 at intervals of 0.001 .

(1942) XXI + 344 pages; bound in buckram, $\$ 2.00$.

[Continued on p. 4 of cover ] 


\section{[Continued from p. 3 of cover}

MT15. The hypergeometric and Legendre functions with applications to integral equations of potential theory. By Chester Snow, National Bureau of Standards. Reproduced from original handwritten manuscript.

(1942) VII +319 pages, bound in heavy paper cover. $\$ 200$.

MT16, Table of Arc Tan $x$ :

Table of inverse tangents for positive values of the angle in radians. Second central differences are included for all entries.

$$
x=\{0(.001) 7(.01) 50(.1) 300(1) 2,000(10) 10,000 ; 12 D]
$$

(1942) XXV +169 pages; bound in buckram, $\$ 2.00$.

MT17. Miscellaneous Physical Tables:

Planck's radiation functions (Originally published in the Journal of the Optical Society of

America, February 1940); and

Electronic functions.

(1941) VII + 58 pages; bound in buckram, $\$ 1.50$.

MT18. Table of the Zeros of the Legendre Polynomials of Order 1-16 and the Weight Coefficients for Gauss' Mechanical Quadrature Formula:

(Reprinted from Bul. Amer. Mathematical Society, Octcbər 1942.)

5 pages with cover. 25 cents.

MT19. On the Function $H(m, a, x)=\exp (-i x) F(m+1-i a, 2 m+2 ; i x)$; with table of the confluent hypergeometric function and its first derivative.

(Reprinted from J. Math. Phys., December 1942.) 20 pages, with cover, 25 cents.

MT20. Table of integrals $\int_{0}^{x} J_{0}(t) d t$ and $\int_{0}^{x} Y_{0}(t) d t:$

Values of the two integrals are given for $x=O(.01) 10$ to 10 decimal places. (Reprinted from J. Math. and Phys., May 1943.) 12 pages, with cover, 25 cents.

MT21. Table of $J i_{0}(x)=\int_{x}^{\infty} \frac{J_{0}(t)}{t} d t$ and Related Functions:

Table I: $J i_{0}(x)$ to 10 decimal places and $F(x)=J i_{0}(x)+\log _{e} 1 / 2 x$ to 12 decimal places for $x=0(.1) 3$ with even central differences of $F(x)$.

Table II: $J_{10}(x)$ to 10 decimal places, for $x=3(.1) 10(1) 22$ with even central differences up to $x=100$.

Table III: "Reduced" derivatives of $F(x)$ for $x=10(1) 21$ and $n=0(1) 13$, to 12 decimal places.

(Reprinted from J. Math. Phys., June 1943.) 7 pages, with cover, 25 cents.

MT22. Table of Coefficients in Numerical Integration Formulae:

The values of $B^{(n)}{ }_{n}(1) / n !$ and $B^{(n)}{ }_{n} / n$ ! where $B^{(n)}{ }_{n}(1)$ denotes the $n^{\text {th }}$ Bernoulli polynomial of the $n$th order for $x=1$ and $B^{(n)}{ }_{n}$ denotes the $n^{\text {th }}$ Bernoulli number of the $n^{\text {th }}$ order, were com. puted for $n=1,2, \ldots 20$. The quantities $B^{(n)}{ }_{n}(1) / n !$ are required in the Laplace formula of numerical integration employing forward differences, as well as in the Gregory formula. The quantities $B^{(n)} n^{\prime} n$ ! are used in the Laplace formula employing backward differences.

(Reprinted from J. Math. Phys., June 1943.) 2 pages, with cover, 25 cents.

MT23. Table of Fourier Coepricients.

Whenever $\varphi(x)$ is a known polynomial whose degree does not exceed 10 , the present table of the functions

$S(k, n)=\int_{0}^{1} x^{k} \sin n \pi x d x$ and $C(k, n)=\int_{0}^{1} x^{k} \cos n \pi x d x$ to $10 D\left(1 \sum k ₹ 10,1 乏 n ₹ 100\right)$, will facilitate the evaluation of the first hundied Fourier Coefficients.

(Reprinted from J. Math. Phys. Sept., 1943.) 11 pages, with cover, 25 cents.

MT24. Coepricients por Numerical Dipherentiation With Central Dipperences.

Coefficients are given for derivatives as far as the 52d. For the first 30 derivatives, exact values are given for coefficients of the first 30 differences, and also exact values are given for some coefficients of differences beyond the 30th. For the other coefficients, values are given to 18 significant figures.

(Reprinted from J. Math. Phys., Sept. 1943) 21 pages, with cover, 25 cents.

Payment is required in advance. Make remittance payable to the "National Bureau of Standards," and send with order, using the blank form facing page 3 of the cover.

A mailing list is maintained for those who desire to receive announcements regarding new tables as they become available. 